\title{
Understanding Display Blindness in Future Display Deployments
}

\author{
Nemanja Memarovic* \\ Department of Informatics \\ University of Zurich \\ memarovic@ifi.uzh.ch
}

\author{
Sarah Clinch* \\ School of Computing \& \\ Communications \\ Lancaster University \\ s.clinch@comp.lancs.ac.uk \\ *Equal contribution by all authors
}

\author{
Florian Alt* \\ Group for Media Informatics \\ University of Munich (LMU) \\ florian.alt@ifi.lmu.de
}

\begin{abstract}
Digital displays are heralded as a transformative medium for communication. However, a known challenge in the domain is that of display blindness in which passersby pay little or no attention to public displays. This phenomenon has been a major motivation for much of the research on public displays. However, since the early observations, little has been done to develop our understanding of display blindness - for example, to identify determining factors or propose appropriate metrics. Hence, the degree to which developments in signage form, content, and interaction address display blindness remains unclear. In this paper we examine and categorize current approaches to studying and addressing display blindness. Based on our analysis we identify open questions in the research space, including the impact of display physicality and audience differences, relationships with other observed effects, the impact of research interventions, and selection of appropriate metrics. The goal of this paper is to start a discussion within the community on the topic, and to inform the design of future research.
\end{abstract}

\section{ACM Classification Keywords}

H.5.2 Information interfaces and presentation: Input devices and strategies; H.5.1 Multimedia Information Systems: Evaluation/Methodology

\section{Author Keywords}

Display blindness, interaction blindness, public displays

\section{INTRODUCTION}

The vision of public displays as a communication medium started in the 1980s when "Hole in Space" [10] connected Los Angeles and New York through a simple video link. Since then, the number of displays in public space has grown considerably $[2,16]$ providing fertile ground for novel research areas including open display networks [9], use of the medium for connecting communities [21, 22], and study of user behavior $[26,27,31]$. As a result of this, a significant number of

Permission to make digital or hard copies of all or part of this work for personal or classroom use is granted without fee provided that copies are not made or distributed for profit or commercial advantage and that copies bear this notice and the full citation on the first page. Copyrights for components of this work owned by others than the author(s) must be honored. Abstracting with credit is permitted. To copy otherwise, or republish, to post on servers or to redistribute to lists, requires prior specific permission and/or a fee. Request permissions from Permissions@ acm.org.

PerDis '15, June 10-12, 2015, Saarbruecken, Germany

Copyright is held by the owner/author(s). Publication rights licensed to ACM. ACM 978-1-4503-3608-6/15/06\$15.00

DOI: http://dx.doi.org/10.1145/2757710.2757719

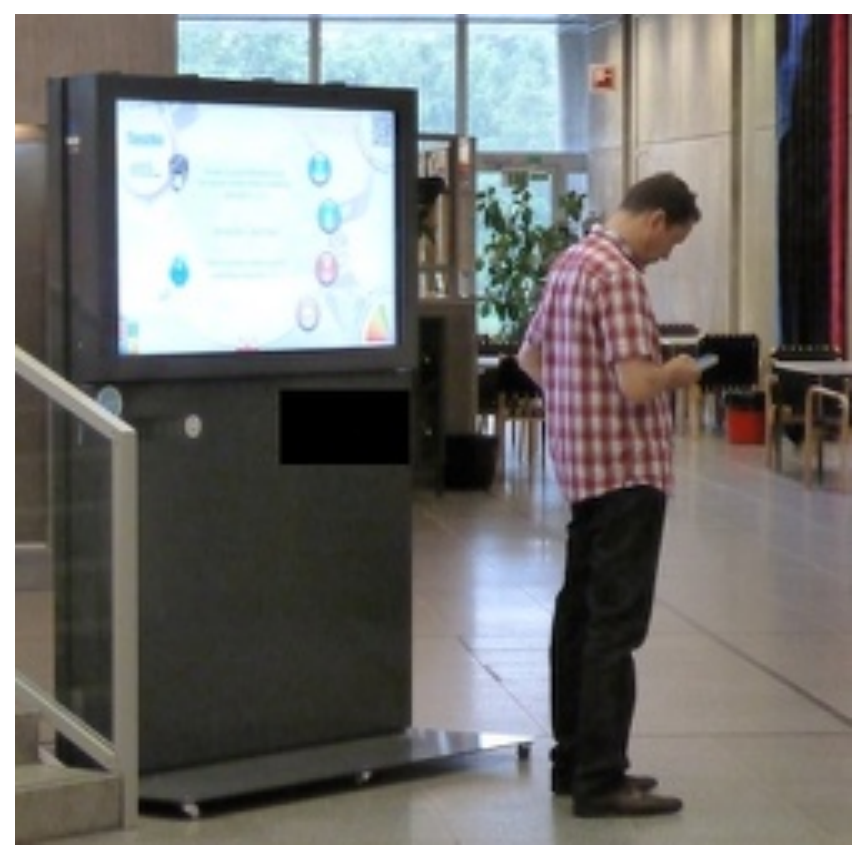

Figure 1. Illustrative example of the display blindness phenomenon where passersby pay little or no attention at public displays.

living labs and "in the wild" display testbeds have emerged, allowing researchers to study key factors in pervasive display deployments [5, 15, 29, 30].

Despite their near-ubiquitous presence in our everyday environments, consensus amongst pervasive display researchers is that deployments are largely undervalued by viewers. While many technical challenges have been solved, thus enabling touch, mid-air gestures, or smartphone-based interaction [3], the overall proportion of passersby that engage with screens remains small [8]. At the outset of any engagement, users are required to notice the display [24]. Yet, passersby often fail to do so and research suggests that this is most likely because they do not expect interesting content [28]. This phenomenon - display blindness - has, since its inception, served as one of the major challenges motivating recent research.

Display blindness was first described in 2008 [14] in a study that looked at 46 large displays located across 24 sites in three cities in central Europe. In their description of a comparative case study, Huang et al. showed that only a small number of people looked at displays $(6.00 \%-16.19 \%)$ and that attention 
of those that did look was short, lasting for only 1-2 seconds. A year later, a follow-up study by Müller et al. looked at passersby's behavior and expectations towards public displays [28]. Studying eleven screens in Münster, Germany, and interviewing 91 participants led the researchers to conclude that people expect uninteresting and boring content on public displays, which ultimately appears to result in a tendency to ignore them. Müller et al. coined the term display blindness to describe this phenomenon and it has continued to be observed in a range of deployments [11, 12, 17, 27].

The two described studies have had considerable influence on pervasive display research, with over 300 citations to date (April 2015). Display blindness has acted as a driver for researchers to find mechanisms and interventions that encourage more users to engage with public displays (for example $[13,17,18,27,32])$. As a result, a rich body of knowledge exists, identifying factors with the potential to influence display blindness. However, to date no attempt has been made to compare these results, and it is unclear how such a comparison could be made. This difficulty stems from a combination of factors. Firstly, the original studies did not suggest any metrics with which to quantify display blindness. Hence, subsequent works have used different approaches, for example, describing the percentage of bystanders that look at a display or by reporting the amount of time spent looking at it. Secondly, results are difficult to relate to each other, simply because studies are typically run in different settings, with different content, using different interaction techniques, etc. Consequently, prior findings remain isolated spots in the design space of display blindness that hinder a comprehensive understanding of (a) what really causes display blindness, (b) how well different approaches perform in addressing it, and (c) whether display blindness changes over time as displays provide more tangible benefits for users.

In this paper we aim to provide a common ground upon which display blindness (and techniques that attempt to address this phenomenon) can be assessed in the future. To do so, we review related work on the topic and identify potential influencing factors that warrant further study. We identify a need for common metrics to describe observations of display blindness such that meaningful comparisons can be made between research, and propose one such methodology for quantifying display blindness based on a synthesis of current practices. In this way we hope to not only establish a commonly accepted "best practice" when it comes to reporting on the success of interventions in public display deployments, but also enable comparative observation of display blindness over time and across different contexts.

The contribution of this paper is threefold:

- We categorize and summarize current approaches on studying display blindness.

- We discuss challenges that come with examining display blindness across settings, display configurations, and user engagement, that should be addressed by future work.

- We propose a methodology that allows display blindness to be compared across deployments.

\section{BACKGROUND AND RELATED WORK}

Prior work has identified four challenges around user engagement with public displays: attracting attention, conveying interactivity, motivating users, and providing understandable interaction techniques [1]. Several phenomena have been identified around these challenges. Following up on the seminal works on display blindness [14, 28], Kukka et al. [17] report on explicit display avoidance where individuals actively turn away from a display. The authors attribute this behavior to the ubiquity of displays in the environment and the resulting information overload.

With regard to the second challenge, Ojala et al. [30] coined the term interaction blindness, referring to the fact that many people do not understand that a given display is interactive. Several projects look at how to address this. Müller et al. suggested showing a representation of the user on the screen (for example, a silhouette or a mirror image) to convey interactivity [27]. Their results showed that this technique significantly increased the number of people interacting, compared to prior approaches, such as calls-to-action. Further research includes the work of Kukka et al. [17] who compared how well different properties of soft buttons convey interactivity as well as the work of Houben and Weichel [13] who suggest the use of a physical 'curiosity' object for inciting interaction.

Despite the aforementioned challenges being clearly important topics, this paper focuses on the fundamental challenge of display blindness since we believe that addressing this is a prerequisite to tackling the other challenges.

Prior research has attempted to identify factors impacting on display blindness and the level of attention directed towards digital displays. Memarovic et al. [19] conducted an observational study around an interactive public display of the 'Screens In The Wild' network ${ }^{1}$. The study described urban distractors - environmental elements that distract passersby from a public display - and their properties: how does a distractor get attention (visual or aural), how dynamic is it (is it static like graffiti or artwork or does it frequently change), and how long does it last (is it temporary like environmental conditions or is it more permanent like graffiti). In parallel, Müller et al. [25] quantified the number of passersby that stop to interact with a public display within a university setting. Their study showed that 3-20\% of passersby interacted with the interactive installation - percentages varied based on the content and the space within the university where the display was located. For the purpose of obtaining these results, Müller et al. deployed two different applications in three contexts over the course of five days in total. Recently, Dalton et al. [7] provided mobile eye trackers to 22 participants, asking them to find a shopping item in a large mall with a high display density. The task took $\sim 15$ minutes. In contrast to the original work, Dalton et al.'s findings show that people always look at some of the displays in the environment, although only briefly $-96 \%$ of the gazes were under $800 \mathrm{~ms}$. Like Müller et al., they agree that such short attention spans are unlikely to happen consciously, however they note that $800 \mathrm{~ms}$ may be enough time to perceive information.

\footnotetext{
${ }^{1} \mathrm{http}: / /$ screensinthewild.org/
} 
From prior work we learn that comprehensively investigating and understanding display blindness through a single study is impossible, due to the complex nature of public displays. Rather, we argue that it will require the commitment of the entire community to address this challenge. By continuing to run studies in different settings and with different content, we hope knowledge to be created, based on which well-grounded conclusions can be drawn in the future. This, however, requires careful reporting of all important aspects. An output of this paper, therefore, is to identify these aspects and to suggest an appropriate methodology for creating such reports.

\section{APPROACHES TO ADDRESSING DISPLAY BLINDNESS}

As researchers have identified display blindness as an important challenge in real-world deployments, a variety of mechanisms for studying and addressing the problem have emerged. These approaches are summarized in Table .

Overall we see a marked shift from measurement of display blindness for non-interactive displays, towards a focus on interactive displays and interaction blindness. In the two original display blindness studies $[14,28]$, the measures used were 1) the number of passersby that glanced at a display, 2) the duration of glances, and 3) people's attitudes and expectations towards display content. Investigated settings included train stations, stores, a travel agency, a library, main buildings of public universities, a cafeteria, a museum and banks for [14] and a university, banks, café, city administration, and a telephone booth for [28]. Most of the content studied was static and displays were non-interactive.

Later studies were more constrained, with a focus on investigating the number of passersby that interact with a display and how to increase this number. Only two studies reported on the duration of glances of passersby at a display, and were compared against findings from the original display blindness study [7, 17]. Apart from [19], further studies exploring why people do not interact with displays have not been conducted. Studies mainly focused on exploring different cues and incites that would attract passersby, with different baseline conditions: no baseline $[17,25]$ vs. some form of incite where the "no incite" was the baseline [13, 25, 27]. Similarly, while original studies investigated a variety of settings, recent studies have primarily focused on university environments [13, $17,25,26]$ and some urban areas - a high-traffic square [19], a shop [27], and a shopping mall [7]. Overall, attitudes to currently available interactive and non-interactive displays have not been thoroughly examined. Kukka et al. [17] asked 32 interviewees what type of content they would expect to see. The duration of recent studies varied: the longest analyses covered periods of 11 [27] and 8 [17] days, other studies typically lasted for 1-2 days [13, 25, 26]. Although display blindness studies have typically been naturalistic, Dalton et al.'s recent eye-tracking study took the form of an in-situ but task-oriented study with recruited participants [7].

\section{OPEN CHALLENGES}

While lab-based studies have offered significant insights into the performance of novel display and interaction technologies, the nature of display blindness requires studies to be conducted in the real-world. Indeed, the phenomenon was only identified in the context of a real-world study. However, whilst real-world studies offer benefits in terms of validity, the influence of individual factors is difficult to identify, particularly when comparing across deployments.

Early display blindness studies attempted to address this through large-scale observations of a range of displays (46 displays over 24 sites [14] and 11 displays over 11 sites [28]). Although more recent studies have provided evidence to support the existence of display blindness [11, 12, 27], these studies have been constrained to single or very small numbers of settings and have focused more on comparing interventions at a single screen rather than at identifying differences between the screens. Returning focus to the topic of display blindness, Dalton et al.'s recent eye-tracking study [7] again compared multiple sites, thus providing additional evidence regarding factors impacting display blindness. Yet, despite the range of settings studied by Huang et al. [14], Müller et al. [28], and Dalton et al. [7], the circumstances in which display blindness is amplified or reduced remain unclear.

Differences in prior studies may be a result of factors such as 1) study duration (couple of hours, a day, around 10 days), 2) baseline used for obtaining the results (no baseline or an application/research specific baseline), 3) reported metrics (descriptive, click rates, conversion rates), and 4) number of displays and their use in the investigation. While most of the studies focused on situated interactions with a single display per location, some had more [7, 27] or investigated the use of networked displays [26]. However, all studies did report on findings specific for a certain geographic locality.

Given the above, we identify a number of open questions:

To what extent do differences in the physical display configurations account for reports of display blindness? Since the original display blindness studies, screens in the lab and in the wild have changed significantly in scale, form factor and their support for interactivity. Isolated display installations are less often the norm, with typical environments much more heavily populated by digital signs. Current display blindness and engagement studies have focussed largely on single display settings (exceptions are [27, 31]), and on traditional flat panel displays. However, exploring the impact of recent trends for interaction, novel display forms etc. will become increasingly important. Even when restricted to simple form factors, current research yields conflicting results with regard to the most commonly studied physical aspect, that of placement above, at, or below eye height $[7,14,12]$; clearly further work is needed to understand these differences in observations.

What user characteristics promote or inhibit display blindness? The social and individual differences between prospective audience members should not be overlooked, and we can immediately identify open questions in this domain. Are there differences between regulars in the setting and strangers? What impact do factors such as age and personality have on display blindness behaviors? Why are findings about the influence of having a captive audience so varied? How does an individual's behavior vary with task, mood, time of day, etc. 


\begin{tabular}{|c|c|c|c|c|}
\hline Study & Metrics / Methods & Settings & Displays / Content & Findings \\
\hline [14] & $\begin{array}{l}\text { Number of people that glanced } \\
\text { at a display. } \\
\text { Glance duration. }\end{array}$ & $\begin{array}{l}\text { Rail station; } \\
\text { travel agency; } \\
\text { banks; library; } \\
\text { university; } \\
\text { cafeteria; } \\
\text { museum; } \\
\text { grocery, book \& } \\
\text { dept. stores. }\end{array}$ & $\begin{array}{l}48 \text { non-interactive } \\
\text { displays: } \\
\text { announcements, } \\
\text { events, } \\
\text { resources, } \\
\text { fun facts, } \\
\text { products, } \\
\text { artistic content }\end{array}$ & $\begin{array}{l}\text { Small percent of people look at a display, e.g. } 6 \% \text { and } 16 \% \\
\text { percent. Glances are short, } 1-2 \text { seconds. The outcomes include } \\
\text { several design recommendations along } 7 \text { categories: brevity of } \\
\text { glances, display position, content format and dynamics, catching } \\
\text { the eye attention of passersby, and differences for large and } \\
\text { small displays. }\end{array}$ \\
\hline [28] & $\begin{array}{l}\text { Number of people looking at a } \\
\text { display } \\
\text { Attitudes towards display } \\
\text { content } \\
\text { Impressions of content }\end{array}$ & $\begin{array}{l}\text { University; } \\
\text { shop window; } \\
\text { bank; } \\
\text { café; } \\
\text { citizen bureau; } \\
\text { clothes store. }\end{array}$ & $\begin{array}{l}11 \text { displays: } \\
\text { student related } \\
\text { information, } \\
\text { television programs, } \\
\text { fashion videos }\end{array}$ & $\begin{array}{l}\text { The first study showed that people's attention for public displays } \\
\text { depended on the context and content. It also showed that } \\
\text { although people had a desirable content in mind for public } \\
\text { displays, they mainly expected to see advertisement. Desirable } \\
\text { content would typically reflect the local surrounding, e.g. news } \\
\text { and information about it. The second study looked more in-depth } \\
\text { at what display properties would likely attract more passersby. }\end{array}$ \\
\hline$[17]$ & $\begin{array}{l}\text { Number of clicks } \\
\text { Qualitative insights: } \\
\text { interviews, } \\
\text { questionnaires }\end{array}$ & University & $\begin{array}{l}8 \text { interactive displays: } \\
\text { single button }\end{array}$ & $\begin{array}{l}\text { Analysis of } 1863 \text { clicks showed that animated colored text } \\
\text { receives most attention. In general, text is preferred over icons, } \\
\text { color over grayscale, and static buttons are preferred over } \\
\text { animated ones. Interview findings showed that passersby would } \\
\text { like to see and interact with highly local content that is } \\
\text { informative, e.g. public transportation schedules, news, } \\
\text { information about lectures etc. Questionnaire data showed that } \\
\text { female participants were more likely than male participants to } \\
\text { report that the displays caught their attention. }\end{array}$ \\
\hline [13] & Conversion rate & University & $\begin{array}{l}1 \text { interactive display: } \\
\text { passive poster, } \\
\text { interactive sketchpad. }\end{array}$ & $\begin{array}{l}\text { Passersby were attracted by an external "curiosity" object. From } \\
825 \text { passersby, } 81(9.82 \%) \text { interacted with the curiosity object. } \\
\text { Of those } 81,76 \% \text { interacted with a display. }\end{array}$ \\
\hline$[19]$ & $\begin{array}{l}\text { Distractors in urban settings } \\
\text { Audience Behavior }\end{array}$ & $\begin{array}{l}\text { High-traffic urban } \\
\text { corner }\end{array}$ & $\begin{array}{l}1 \text { interactive display: } \\
\text { Moment Machine }\end{array}$ & $\begin{array}{l}\text { Classification of different urban elements that compete for } \\
\text { passersby attention and distract them from interacting with a } \\
\text { public display. }\end{array}$ \\
\hline [27] & Conversion rate & $\begin{array}{l}\text { Shop in an urban } \\
\text { setting in Berlin }\end{array}$ & $\begin{array}{l}3 \text { interactive displays: } \\
\text { ballgame (mirror, } \\
\text { silhouette, no hint) }\end{array}$ & $\begin{array}{l}\text { Overall, analysis of } 502 \text { interaction sessions recorded over } 11 \\
\text { days were analyzed. Passersby reacted the most to inadvertent } \\
\text { mirrored video feed. }\end{array}$ \\
\hline [26] & Conversion rate & $\begin{array}{l}\text { University } \\
\text { (6 locations) }\end{array}$ & $\begin{array}{l}6 \text { interactive displays: } \\
\text { connected media } \\
\text { space }\end{array}$ & $\begin{array}{l}\text { The more people interact with a public displays, the more } \\
\text { attention they receive from bystanders. This also applies across } \\
\text { a display network, i.e., seeing people interact on one of the } \\
\text { displays attracts other passersby to interact at remote locations. }\end{array}$ \\
\hline [25] & Conversion rate & University & $\begin{array}{l}1 \text { interactive display: } \\
\text { game (cubes, water } \\
\text { particles) }\end{array}$ & $\begin{array}{l}\text { Initial study showed that call-to-action button attracts more } \\
\text { attention than a standard button ( } 697 \text { passersby, } 66 \text { interacted). } \\
\text { In the second experiment the water version of the application } \\
\text { was deployed in } 2 \text { settings, i.e., university corridor and university } \\
\text { hall. Findings from } 117 \text { users out of } 718 \text { passersby showed that } \\
\text { people engaged more in the corridor ( } 20 \% \text { vs. } 12 \%) \text {. In the third } \\
\text { experiment two versions of the application were deployed for two } \\
\text { days. Findings showed that passersby engaged more with the } \\
\text { water content ( } 12 \% \text { vs. } 3 \%) \text {. }\end{array}$ \\
\hline$[7]$ & $\begin{array}{l}\text { Number of glances and glance } \\
\text { duration }\end{array}$ & $\begin{array}{l}\text { Large shopping } \\
\text { mall }\end{array}$ & $\begin{array}{l}\text { Up to } 337 \text { interactive } \\
\text { and non-interactive } \\
\text { displays were } \\
\text { potentially visible } \\
\text { during their task. } \\
\text { Interactive displays } \\
\text { were access } \\
\text { directories with } \\
\text { information about mall } \\
\text { venues, and also } \\
\text { supported way-finding. }\end{array}$ & $\begin{array}{l}\text { The longest gaze on a display was } 2.1 \text { seconds, while most of } \\
\text { the participants looked at a display for a maximum of } 0.8 \\
\text { seconds. Most of the glances were below } 800 \mathrm{~ms}(96 \%) .50 \% \text { of } \\
\text { the participants looked at a display from afar first, at a distance } \\
\text { greater than } 8 \mathrm{~m} \text {. Contrary to Huang et al. that people rarely look } \\
\text { at displays that are above eye height, } 25 \% \text { of the displays that } \\
\text { were observed were above eye height. Of their } 12 \text { reference } \\
\text { displays, } 1 \text { was looked at by all the participants, } 1 \text { by } 60 \%, 5 \\
\text { were looked at by } 40-50 \%, 3 \text { between } 20 \text { and } 30 \% \text {, and one } \\
\text { was not attended to at all. }\end{array}$ \\
\hline
\end{tabular}

Table 1. Summarized description of studies on the display blindness phenomenon.

Through observations, some of these factors have naturally emerged. For example, researchers have noted that passing a display in a group may yield different behavior [23]; that over time regular revisiting by some individuals may occur $[20,27])$; that different times of the day appear to yield different levels of engagement [20]; and that competing tasks (e.g. being on the phone) may impact environmental attention [12]. We identify a need for further systematic consideration of these areas, and some unresolved audience factors that have been moderately well studied (e.g. the differing reported impacts of a 'captive' audience in $[14,28]$ ).
What is the relationship between display blindness, and other engagement effects observed in the digital signage space? A range of engagement behaviors have been observed around displays, and some researchers have also suggested that attachment and similar behaviors seen for other devices may transfer to the display domain (e.g. [18]). Understanding how display blindness intersects with these different engagement behaviors is also a valuable area for further study. For example, how do the observed display blindness and interaction blindness effects impact upon each other? How much is display avoidance a distinct behavior from display blindness, and how much is it simply a different interpretation of 
the same behavior? Indeed, perhaps display blindness itself is less common than anticipated (as suggested by Dalton et al.'s recent results [7]), and much of what has been seen in earlier studies has in fact been illustrations of the more recently identified 'display avoidance' problem. A further simple example in this area is consideration for novelty effects - documented examinations of the display and interaction blindness problems have typically been relatively limited with respect to time.

To what extent do research interventions impact display blindness? Although display blindness studies have typically spanned a range of deployments, evaluations of engagement interventions (for example, calls-to-action) have often been far more restricted in setting. Short-scale deployments in these limited settings have provided valuable results, but still open is the question of how well changes in engagement persist over time and beyond the deployment space. For example, given an experience of an experimental deployment (for example, those in [13, 25, 27]), does a user then go on to engage more or less with other deployments, and do their expectations of those deployments change? Furthermore, following on from the description of the novelty effect above, do specific interventions continue to have an impact on engagement - that is, how long lasting are changes in attitude?

Understanding these factors could transform the research domain. Current research is unable to determine if the limited engagement between passersby and displays is a problem that can be overcome by improvements in deployments, the emergence of new interaction patterns etc., or if, in the long run, interactions with public displays are simply short and not as engaging as other media, such as smartphones and Facebook. Furthermore, we have no clear understanding if few, short engagements are really limiting display effectiveness (indeed, a recent study showed that displays can prompt stable engagements that, although short, still have an effect on users [20]).

What is a good baseline? What tools and metrics should we use? Studies to date have incorporated very varied metrics and baselines, and only one recent study has compared findings against the display blindness frequencies observed in early studies. Given discrepancies in both method and findings, it is difficult to understand how much the results are simply a product of the measures being used (for example, number and duration of glances, accurate recollection of content). The recent use of eye tracking as an alternative to observations for measuring glances [7] compounds this challenge, as current understanding does not indicate the success of this method. Understanding how to evaluate the display blindness effect is an important challenge and we believe that in order to inform future research more constructively some sort of a standard baseline condition and metric should be established.

\section{METHODOLOGY TO INVESTIGATE DISPLAY BLINDNESS}

A key challenge identified is that of understanding the significance of differences between deployments when measuring engagement. Real-world study is clearly the most effective method of measuring display and interaction blindness, but differences in setting and methodology between studies are unavoidable. Adopting a set of common metrics for the description of pervasive display deployments and in-situ experimental methods would allow researchers to make more meaningful comparison between studies. We therefore suggest a foundation set of metrics and best practices for the description of in-situ pervasive display studies. As future research adopts these (1) a better comparisons of work conducted in the area of pervasive displays is enabled and (2) display blindness as a major issue that hinders a more widespread uptake of interactive displays can be comprehensively understood.

\section{Report}

Following Dalsgaard et al.'s practice for media facades [6], we suggest the following information for each deployment to be reported. Firstly, authors should describe the content running on the display including interaction techniques and the purpose of the application. Secondly, the location, i.e., the surrounding area should be described. In particular any aspects that potentially impact on the number of people interacting should be reported. Thirdly, screen properties, such as the size, orientation, and operation hours should be reported. Ideally, numbers would be reported for meaningful time periods (commuting hours, lunch break, weekends).

\section{Metrics \\ We suggest that for each display deployment overall duration of the deployment or observations, the number of passersby, the number of people looking, and the number of people in- teracting be reported. This should include the average glance duration and, if applicable, average interaction session.}

To understand the impact of a deployment, numbers from different points in time during the deployment are of interest. Firstly, numbers from before the deployment are interesting, in case a display has been previously used to show different content. This provides a valuable baseline since the audience may have built up a certain expectation towards the display. Secondly, numbers early in the deployment allow a potential novelty effect to be quantified. Thirdly, numbers at the end of the deployment are most interesting, since they reflect the degree to which a deployment manages to overcome display blindness beyond the novelty effect.

For longer deployments, different types of users should also be accounted for, i.e., a clear difference between the number of returning users (e.g., people passing the display regularly) and non-returning users (one-time visitors) [20]. From a qualitative side, the report should capture users' attitudes toward interactive and non-interactive displays, as well as accounts for where they expect to see potential changes (accounting for the changes in their attitude over time and location).

\section{Best Practice}

A sample report, incorporating the information and metrics suggested above, is provided in Table 2. Following the name of the deployment, a summary of deployment / observation duration, display content, location (with representative images, if possible), screen properties, and user attitude toward public displays in general allows the reader to quickly grasp the most important information about the project. 


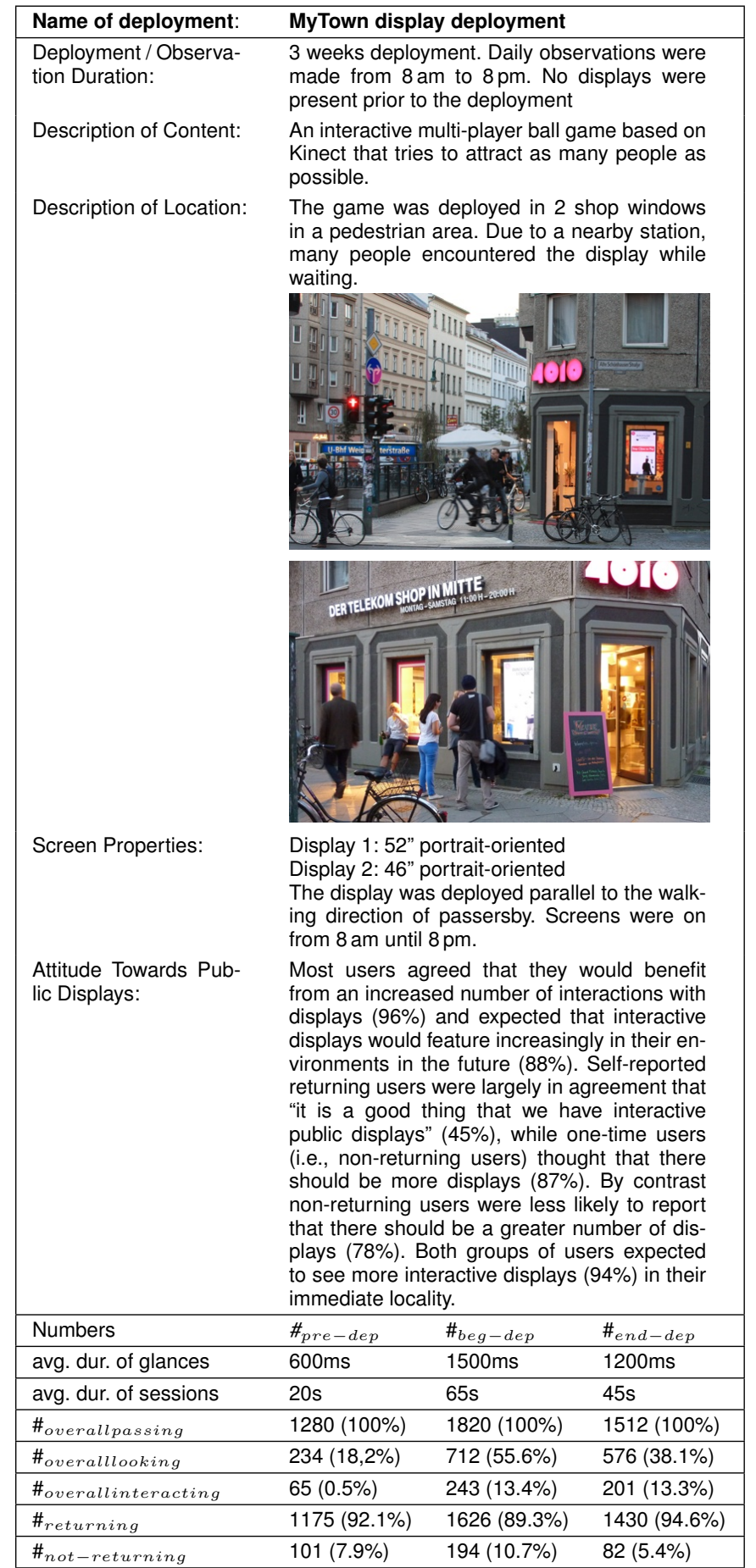

Table 2. Sample report for a public display deployment, providing information on the duration, content, location, screen properties and audience attitude. The report is complemented by numbers of users and information on the average duration of glances and interaction (before, at the beginning, and at the end of the deployment.

Next, data on the overall number of people passing, looking, and interacting is reported, followed by the average glance duration, and, if applicable, the average interaction session. Finally, numbers on regular returning users and non-returning users would be presented - however this would be done only in cases where such data would be possible to obtain, e.g., for applications that use situated snapshots [20] or those that use live video [27, 26, 25, 29]. This would optimally allow for a comparison prior to, at the beginning, and at the end of the deployment. Conversion rates allow the success to be quantified and related to other deployments. Similar reports have already started to appear, e.g., as in [4].

\section{CONCLUSION}

Since the first observations of display blindness in 2008, researchers and digital signage innovators have been motivated to develop a range of techniques for encouraging passersby to engage with the displays in their environment. Despite significant technical progress (in terms of enabling novel interactions), there is little to demonstrate that these innovations are genuinely reducing the occurrence of display blindness in the field. Indeed, researchers' understanding of the display blindness phenomenon is largely restricted to the outcomes of the two seminal papers that identified the problem $[14,28]$. Although valuable, these work never intended to identify a definitive set of factors impacting display blindness, and indeed in some cases provided contradictory evidence that warranted further exploration (e.g. impact of a captive audience).

In this paper we have summarized current research studying and addressing the problem of display blindness. We have categorized approaches used to explore the issue (Table ) and identified a series of key challenges that impact the research community's efforts to study and report display blindness in a consistent and comparable manner. Our work has two parallel aims: acting both to inform the design of future research that will examine and study display blindness; and to prompt further consideration of the issue within the community beyond simply acting as a motivation for the development of novel engagement techniques. We hope that this paper marks the beginning of an ongoing discussion within the research community on how to examine and report on the problem of display blindness, and ultimately to develop broader consensus within the community.

\section{ACKNOWLEDGMENTS}

We thank Jörg Müller for his valuable input to this work. This research is partially funded through the Future and Emerging Technologies (FET) programme within the 7th Framework Programme for Research of the European Commission, under FET grant number: 612933 (RECALL).

\section{REFERENCES}

1. Alt, F. A design space for pervasive advertising on public displays. Ph.D. thesis, Univ. of Stuttgart, 2013.

2. Alt, F., Müller, J., and Schmidt, A. Advertising on Public Display Networks. IEEE Computer 45, 5 (May 2012), 50-56.

3. Alt, F., Shirazi, A. S., Kubitza, T., and Schmidt, A. Interaction techniques for creating and exchanging content with public displays. In Proceedings of CHI'13, ACM (2013). 
4. Claes, S., Wouters, N., Slegers, K., and Vande Moere, A. Controlling in-the-wild evaluation studies of public displays. In Proceedings of CHI '15, ACM (2015).

5. Clinch, S., Davies, N., Friday, A., and Efstratiou, C. Reflections on the long-term use of an experimental digital signage system. In Proceedings of Ubicomp '11 (2011).

6. Dalsgaard, P., Halskov, K., and Nielsen, R. Towards a design space explorer for media facades. In Proceedings of OzCHI '08, ACM (2008).

7. Dalton, N., Collins, E., and Marshall, P. Display blindness? looking again at the visibility of situated displays using eye tracking. In Proceedings of CHI '15, ACM (2015).

8. Davies, N., Clinch, S., and Alt, F. Pervasive Displays Understanding the Future of Digital Signage. Synthesis Lectures. Morgan and Claypool Publishers, 2014.

9. Davies, N., Langheinrich, M., José, R., and Schmidt, A. Open display networks: A communications medium for the 21st century. IEEE Computer 45 (2012).

10. Galloway, K., and Rabinowitz, S. Hole-In-Space. http://www.ecafe.com/getty/HIS/, 1980.

11. Goncalves, J., Ferreira, D., Hosio, S., Liu, Y., Rogstadius, J., Kukka, H., and Kostakos, V. Crowdsourcing on the spot: Altruistic use of public displays, feasibility, performance, and behaviours. In Proceedings of Ubicomp '13, ACM (2013).

12. Hardy, J., Rukzio, E., and Davies, N. Real world responses to interactive gesture based public displays. In Proceedings of MUM '11, ACM (2011).

13. Houben, S., and Weichel, C. Overcoming interaction blindness through curiosity objects. In $C H I$ ' 13 EA, ACM (2013).

14. Huang, E. M., Koster, A., and Borchers, J. Overcoming assumptions and uncovering practices: When does the public really look at public displays? In Proceedings of Pervasive '08, Springer (2008).

15. Jose, R., Pinto, H., Silva, B., and Melro, A. Pins and posters: Paradigms for content publication on situated displays. Computer Graphics and Applications, IEEE 33, 2 (March 2013), 64-72.

16. Kostakos, V., and Ojala, T. Public displays invade urban spaces. IEEE Pervasive Computing 12, 1 (Jan. 2013), 8-13.

17. Kukka, H., Oja, H., Kostakos, V., Gonçalves, J., and Ojala, T. What makes you click: Exploring visual signals to entice interaction on public displays. In Proceedings of CHI'13, ACM (2013).

18. Lee, K., Clinch, S., Winstanley, C., and Davies, N. I love my display: Combatting display blindness with emotional attachment. In Proceedings of PerDis '14, ACM (2014).
19. Memarovic, N., Fatah gen. Schieck, A., Kosotopoulou, E., Behrens, M., and Al-Sayed, K. Attention, an interactive display is running! integrating interactive public display within urban dis(at)tractors. Screencity Jour. 4 (2014).

20. Memarovic, N., Fatah gen. Schieck, A., Schnädelbach, H., Kosotopoulou, E., North, S., and Ye, L. Capture the moment: "in the wild" longitudinal case study of situated snapshots captured through an urban screen in a community setting. In Proceedings of CSCW'15, ACM (2015).

21. Memarovic, N., Langheinrich, M., and Alt, F. Connecting People through Content - Promoting Community Identity Cognition through People and Places. In Proceedings of Comm. Inf. (2011).

22. Memarovic, N., Langheinrich, M., and Fatah gen. Schieck, A. Community is the message: Viewing networked public displays through mcluhan's lens of figure and ground. In Proceedings of MAB '14, ACM (2014).

23. Michelis, D., and Müller, J. The audience funnel: Observations of gesture based interaction with multiple large displays in a city center. International Journal of Human-Computer Interaction 27, 6 (2011), 562-579.

24. Müller, J., Alt, F., Michelis, D., and Schmidt, A. Requirements and design space for interactive public displays. In Proceedings of MM '10, ACM (2010).

25. Müller, J., Bailly, G., Bossuyt, T., and Hillgren, N. Mirrortouch: Combining touch and mid-air gestures for public displays. In Proceedings of MobileHCI '14, ACM (2014).

26. Müller, J., Eberle, D., and Tollmar, K. Communiplay: A field study of a public display mediaspace. In Proceedings of CHI'14, ACM (2014).

27. Müller, J., Walter, R., Bailly, G., Nischt, M., and Alt, F. Looking glass: A field study on noticing interactivity of a shop window. In Proceedings of CHI '12, ACM (2012).

28. Müller, J., Wilmsmann, D., Exeler, J., Buzeck, M., Schmidt, A., Jay, T., and Krüger, A. Display blindness: The effect of expectations on attention towards digital signage. In Proceedings of Pervasive '09, Springer (2009).

29. North, S., Schnädelbach, H., Fatah gen Schieck, A., Motta, W., Ye, L., Behrens, M., and Kostopoulou, E. Tension space analysis: Exploring community requirements for networked urban screens. In Proceedings of INTERACT '13. Springer, 2013.

30. Ojala, T., Kostakos, V., Kukka, H., Heikkinen, T., Linden, T., Jurmu, M., Hosio, S., Kruger, F., and Zanni, D. Multipurpose interactive public displays in the wild: Three years later. IEEE Computer 45, 5 (May 2012), $42-49$. 
31. Ten Koppel, M., Bailly, G., Müller, J., and Walter, R. Chained displays: Configurations of public displays can be used to influence actor-, audience-, and passer-by behavior. In Proceedings of CHI '12, ACM (2012).
32. Wang, M., Boring, S., and Greenberg, S. Proxemic peddler: A public advertising display that captures and preserves the attention of a passerby. In Proceedings of PerDis '12, ACM (2012). 